\title{
Evaluation of Potential Wind Energy Sites in the Province of Essaouira in Morocco
}

\author{
http://dx.doi.org/10.3991/ijes.v3i3.4391 \\ Daoudi Mohammed, Elkhouzai Elmostapha, Zakkari Mohammed \\ University Hassan $1^{\text {st }}$, Settat, Morocco
}

\begin{abstract}
The main objective of this study was to assess the wind potential of the JBEL HDID site in Essaouira. First, we give a brief overview of the current status of wind energy in the world and in Morocco. Initial lines of reflection led us to develop a methodology for developing a wind farm. The implementation of this methodology allowed us to model the wind in three sites in the region, using data from the wind of the three masts installed in the region and data from nearby sites. Secondly, measurements were taken over a one year cycle. Then they were compared with the data of winds at a meteorological station chosen for the quality of its correlation with measurements registered during the year and for which it is possible to go back in time for as long a period as possible; thus, we would know by statistical formulas if the measurements of this year were representative of all years in this area. Finally, a comparison was made between the wind turbines from different manufacturers with various configurations to make a preliminary design for the park and calculate the electrical energy that could be produced by it.
\end{abstract}

Index Terms - potential wind, wind farm, preliminary design, Vertical Extrapolation, reference stations, Method Measurement Correlations Predictions.

\section{INTRODUCTION}

Climatology is the scientific study of climate with practical applications. It uses the same database as meteorology. The applications are endless since most human activities are conditioned by time. Thus, the results find practical applications in the fields of industry, agriculture, and transportation.

Time scale is a major difference between meteorology and climatology. Meteorology deals with phenomena whose duration varies from a few seconds to a dozen days, while climatological phenomena are extended based on seasons, years, decades, or even more.

Wind meteorology appeared as an applied science to meet a particular need. To ensure the efficiency of implementation, you have to locate the areas favorable for the installation of wind turbines and simulate the wind potential of a given site. Wind meteorology is strictly based on the atmospheric boundary layer and in particular on the geophysical fluid dynamics. It consists of three major parts: evaluation of the wind resource in some geographic region, short-term prediction of this resource, and choice of the positions of the wind turbines (micro siting).

The data used in this discipline were derived primarily from the following sources: wind measurements in situ to exploration of the site, the synoptic network from the National Center for Atmospheric Research (NCAR) [1], and the outputs modeled for numerical analysis. Studies of climatology wind are estimates of the wind resource, and position choices for wind turbines require knowledge of the topographical area. This implies a detailed description of the surface roughness, the obstacles located around it, and the orography of the terrain. An evaluation of the wind resource involves an estimate producible for multiple machines distributed over a geographical region.

The present paper provides the methodology developed to complete the study. The application of this methodology primarily resulted in an assessment of the wind potential of a site based on reference site data.

\section{A. World wind power Situation}

The International Energy Agency (IEA) estimates that by $2020,12 \%$ of the world's electricity will be produced from the wind [2]. Electricity usage in the world will be on this horizon in the order of $25578 \mathrm{TWh}$, which requires the production of 3,000 TWh/year from wind power. A number of studies worldwide (including from the BTM Consult Research Institute in Denmark) confirmed the importance of the development of the capacities of wind farms in the coming years. This dynamic is mainly due to important wind resources identified at the global level, the development of wind turbine technology, lower production costs per $\mathrm{kWh}$ wind, tax and regulatory incentives granted by the states and the political will to develop this sector in several countries, including European.

The worldwide wind capacity reached 336 '327 MW by the end of June 2014, out of which 17'613 MW were added in the first six months of 2014. This increase is substantially higher than in the first half of 2013 and 2012, when 13.9 GW and 16.4 GW were added, respectively.

The total worldwide installed wind capacity by mid2014 generated around $4 \%$ of the world's electricity demand. The global wind capacity grew by $5.5 \%$ within six months (after $5 \%$ in the same period in 2013 and $7.3 \%$ in 2012 ) and by $13.5 \%$ on an annual basis (mid-2014 compared with mid-2013).

In comparison, the annual growth rate in 2013 was lower, at $12.8 \%$. Reasons for the relatively positive development of the worldwide wind markets include the economic advantages of wind power and its increasing competitiveness relative to other sources of electricity as well as the pressing need to implement emission free technologies to mitigate climate change and air pollution.

The five traditional wind countries - China, USA, Germany, Spain and India - still collectively represent a $72 \%$ share of the global wind capacity. In terms of newly added capacity, the share of the Big Five has increased from $57 \%$ to $62 \%$. 
The Chinese market showed a very strong performance and added $7.1 \mathrm{GW}$, substantially more than in the preceding years. China reached a total wind capacity of $98 \mathrm{GW}$ in June 2014 and has undoubtedly by now crossed the 100 GW mark.

Germany performed strongly as well, adding $1.8 \mathrm{GW}$ within the first half of 2014. This new record no doubt comes partly in anticipation of changes in the renewable energy legislation, which may lead to a slow-down of the German market in the coming years. For the first time, Brazil has entered the top group by becoming the third largest market for new wind turbines, with $1.3 \mathrm{GW}$ of new capacity, representing $7 \%$ of all new wind turbine sales. With this, Brazil has been able to extend its undisputed leadership in Latin America.

India clearly kept its position as Asia's number two and worldwide as number five, with $1.1 \mathrm{GW}$ of new wind capacity.

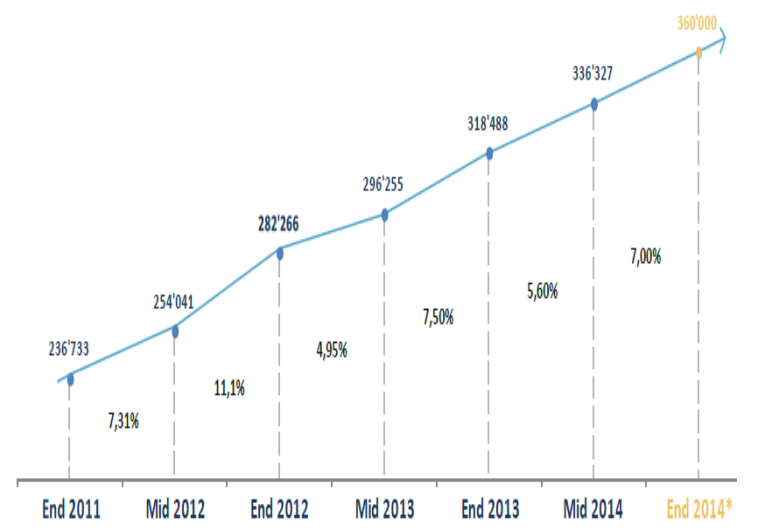

Figure 1. Total Installed Capacity 2011-2014 (MW)

The US market, after its effective collapse in 2013, has shown strong signs of recovery, with a market size of 835 MW, slightly ahead of Canada (723 MW), Australia (699 MW) and the United Kingdom, which halved its market size and installed $649 \mathrm{MW}$ in the first half of 2014. The Spanish market, however, did not contribute to the overall growth in 2014, as it came to a virtual standstill, with only $0.1 \mathrm{MW}$ of new installations in the first half of 2014. As was the case in 2013, four countries installed more than 1 GW each in the first half of 2014: China (7.1 GW of new capacity), Germany (1.8 GW), Brazil (1.3 GW), and India $(1.1 \mathrm{GW})$.

The top ten wind countries show a similar picture in the first half of 2014, although on a slightly higher performance basis. Five countries performed stronger than in 2013: China, USA, Germany, France and Canada. Five countries saw a decreasing market: Spain, UK, Italy, Denmark, and, to a lesser degree, India. Spain and Italy practically saw a total standstill, with only $0.1 \mathrm{MW}$ and 30 MW, respectively, of new capacity installed. Poland is now in the list of the top 15 countries for installed capacity, while Japan dropped out.

\section{B. National energy situation}

In Morocco, the energy bill represents a significant burden on the trade balance. Indeed the exploitable conventional energy resources are limited; the country depends almost entirely on the outside for its energy supply (the energy dependence rate stood at 95\%) [3].
This situation prompted the government to implement an energy strategy based on securing supply and diversification of energy sources, including the production of electricity through the use of national energy resources. Wind energy is a free source of energy and is available in several regions of Morocco (Fig.2), which can satisfy a portion of the power consumption and reduce oil imports [3]. The different studies by the National Agency for the development of renewable (ADEREE) allowed the identification of interesting windy sites used for the implementation or development of large wind farm projects. In terms of achievement, the output from the two wind farms of 50 MW and $3 \mathrm{MW}$ achieved in the north (Wind Farm Abdelkhalek Torres) was 206.3 GWh. Furthermore, new applications of wind energy in Morocco will develop rapidly, particularly for the desalination of sea water and hydrogen production.

Taking into account the contribution of Great Hydraulics, with $2.210 \mathrm{GWh}$ (rainfall in a normal year), the producible renewable energy in 2014 will represent $20 \%$ of the national electricity balance and $10 \%$ of the national energy balance, as shown in Fig.3 [4].

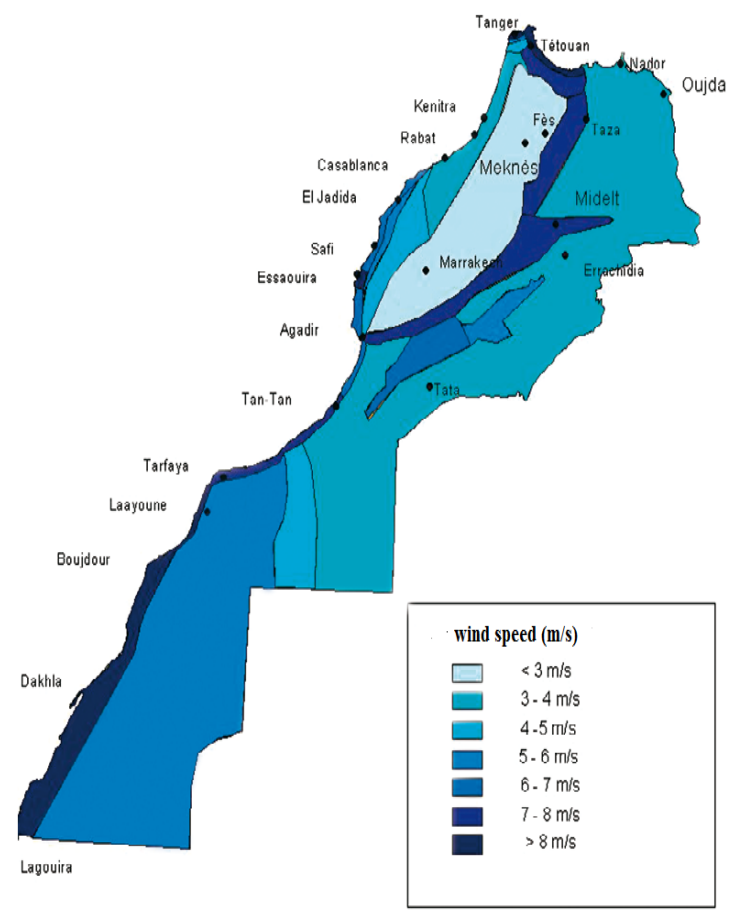

Figure 2. Wind map of Morocco

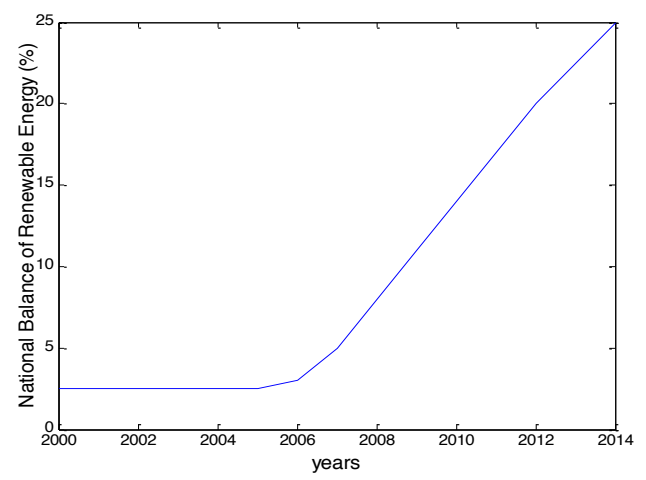

Figure 3. Evolution of the contribution RE to the national energy balance 
Realizable Potential in 2020 [3]

- $4.000 \mathrm{MW}$ to $7.000 \mathrm{MW}$;

- 6 to 10.5 billion $€$ Investments;

- 9 to 15 million tons/year of $\mathrm{CO} 2$ was avoided;

- 2.6 to 4.4 million tons of oil equivalent/year saved;

- 20,000 jobs created.

Morocco has considerable potential for wind power, estimated at 25.000 MW; 6.000 MW are feasible in sites identified in the regions of Essaouira, Tangier and Tetouan, with wind speeds ranging from 9.5 to $11 \mathrm{~m} / \mathrm{s}$ in regions of Dakhla, Laayoune and Taza (between 7.5 and $9.5 \mathrm{~m} / \mathrm{s}$ ) [3].

Five potential new sites were chosen to accommodate wind farms with a total capacity of $1.000 \mathrm{MW}$ (Tanger II sites, Koudia El Baida in Tetouan, Taza, Laayoune and Haouma in Tetouan).

These wind farms are in addition to Essaouira and Tangier with $280 \mathrm{MW}$ of wind power, and those of Tarfaya, Akhfenir, Bab El Oued in Laayoune and Haouma in Tetouan (720 MW in development) [4].

\section{A. Essaouira}

\section{1) Geographical situation}

Essaouira is a city located in the south of Morocco, $350 \mathrm{Km}$ from the economic Casablanca metropolis, 175 $\mathrm{km}$ west of Marrakech and $170 \mathrm{~km}$ north of Agadir. Essaouira is the administrative center of a province $\left(6335 \mathrm{~km}^{2}\right)$ with about 433.683 inhabitants (including 75.437 in Essaouira); it extends over thirty hectares. A site $39 \mathrm{Km}$ northeast of Essaouira [4] was our target station where the wind potential was evaluated through the steps already mentioned.

\section{2) Climatology}

The climate province of Essaouira is arid, with a large dry period of six to seven months. Aridity is a decreasing gradient from east to west. To the east, rainfall drops and temperatures rise. To the west, in the narrow coastal strip around the city of Essaouira, the influence of the cold Canary Current determines a microclimate with an average homogenous temperature throughout the year. The average temperature of the city of Essaouira is $16.7^{\circ} \mathrm{C}$, with a relatively small difference between the average temperatures of the warmest month and the coldest month [4]. High winds are a constant in the city of Essaouira. The dominant directions are the north with a frequency of $30 \%$ and the northeast with a frequency of $24 \%$. The number of days of high wind (over $16 \mathrm{~m} / \mathrm{s}$ ) was estimated at 123 days per year.

\section{SELECTION OF THE REFERENCE SITE AND WIND STUDY}

Most of the time, the choice is limited to the nearest metrological station.

\section{A. Using the Weibull distribution to compare sites}

The probability density function is given by:

$f(V)=\frac{K}{C}\left(\frac{V}{C}\right)^{K-1} \exp \left|-\left(\frac{V}{C}\right)^{K}\right|$

The cumulative distribution function is given by: $F=\exp \left|\left(\frac{V}{C}\right)^{K}\right|$
The $\mathrm{V}$ value average and standard deviation $\sigma$ of the distribution are expressed using the $\Gamma$ function:

$V=C \Gamma\left(\frac{1}{K}+1\right)$

$\sigma=C\left|\Gamma\left(1+\frac{2}{K}\right)-\Gamma^{2}\left(1+\frac{1}{K}\right)\right|$

$\Gamma$ is an Eulerian function of the second kind defined by:

$\Gamma(x)=\int_{0}^{\infty} t^{x-1} \exp (-t) d t$

With $x \geq 0 ; t=\left(\frac{V}{C}\right)^{K} ;(x-1)=\left(\frac{1}{K}\right)$

The integration of $f(v)$ between $\mathrm{V}$ and $\infty$ give the expression of the distribution function $f(v)$. To represent the distribution of the wind frequency using the Weibull distribution, there is a probability density function:

$f(v)=\left(\frac{k}{C}\right)\left(\frac{V}{C}\right)^{k-1} \exp \left(\frac{-V}{C}\right)^{k}$

Where $\mathrm{f}(v)$ is the probability density at the speed $V$ $(\mathrm{m} / \mathrm{s}), K$ is the shape of the curve factor (dimensionless), $C$ is the scale of the curve factor in $\mathrm{m} / \mathrm{s} . \mathrm{K}$ and $\mathrm{C}$ parameters are determined by:

$K=1+0,483(V-2) 0,51$

$C=1.125 \frac{V}{(1-B)}$ for $1.5<k<3$

$B=1-0.89(V-2) 0.89$

Where $V$ represents the average wind speed (Values of $K$ and $C$, which calculated by the above formulas are approximate).

It is highly advisable to compare the shape parameter $K$ for the measurement site to the reference site.

- If the shape parameter of the site studied is much lower than that of the reference station, the study site is most probably a bad location in relation to the regional flow.

- If the scale parameter A is too low, there is a chance to obtain sufficient wind resources by increasing height; if for the shape parameter, the chances are greatly reduced.

To evaluate the potential wind in the region of JBEL HDID, three masts $10 \mathrm{~m}$ installed at three different sites were analyzed and compared with the climatologically reference sites, as shown in Table I.

TABLE I.

POSITIONS OF THE THREE STUDIED SITES

\begin{tabular}{|c|c|c|}
\hline site & Latitude & Longitude \\
\hline $\begin{array}{l}\text { CAP HDID } \\
\text { CAP SIM } \\
\text { AISSI }\end{array}$ & $\begin{array}{l}\text { N 31 } 1^{\circ} 46^{\prime} 23.540^{\prime \prime} \\
\text { N } 31^{\circ} 23^{\prime} 20.280^{\prime \prime} \\
\text { N } 31^{\circ} 9^{\prime} 9.320^{\prime \prime}\end{array}$ & $\begin{array}{l}\text { W } 9^{\circ} 29^{\prime} 42.000^{\prime \prime} \\
\text { W } 9^{\circ} 47^{\prime} 56.150^{\prime \prime} \\
\text { W } 9^{\circ} 45^{\prime} 46.840^{\prime \prime}\end{array}$ \\
\hline
\end{tabular}

\section{B. Reference to regional wind resource}

Often called the regional wind resource, the wind potential exists above the layer of the atmosphere in which wind flow is modified by the influence of the soil. The 
PAPER

Evaluation of Potential Wind ENERgy Sites In the Province of Essaouira IN Morocco

thickness of this layer is between 500 and $1500 \mathrm{~m}$, depending on weather conditions and latitude. Understandably, in areas bordering the sea or when wind coming from the sea is predominant, the metrological stations installed on shore will be more readily representative of the regional wind resource than stations located behind or in the middle reliefs relative to dominant winds. While the choice of reference stations was open, we first selected metrological stations that are most representative of the regional wind resource, even if the measurement series length is shorter than in other stations that are less representative and more poorly located.

\section{Wind Study}

A few changes in the wind can induce a significant difference in the economic performance of a wind farm. If preliminary projections make it possible to locate potential sites, then it is necessary to detail:

- In situ measurements of the wind

- Analysis of the behavior of the wind in time

- Analysis of wind behavior on the site

It is also at this level that the long-term data are constructed to estimate average speeds and wind direction over a long period (preferably over 5 years). To evaluate the potential wind to the region of JBEL HDID three masts of $10 \mathrm{~m}$ installed on three different sites were analyzed and then compared with the reference climatological site.

The objective of the wind data analysis on these sites was to show these variations to verify that the energy supplied by the wind would be sufficient. Analysis over a long term allows observation of the period of changes. Therefore, 9 to 12 months of measurements were necessary to evaluate the periodic variations in speeds.

TABLE II.

MEASUREMENT OF MASTS FOR CAPHDID, CAPSIM AND AISSI SITES

\begin{tabular}{|c|c|c|c|}
\hline site & $\begin{array}{c}\text { CAP } \\
\text { HDID }\end{array}$ & $\begin{array}{l}\text { CAP } \\
\text { SIM }\end{array}$ & AISSI \\
\hline Height of the measurement (m) & 10 & 10 & 10 \\
\hline Temperature $\left({ }^{\circ} \mathrm{C}\right)$ & 20.1 & 19.9 & 20.1 \\
\hline Duration (months) & 12 & 8.3 & 12 \\
\hline Average wind speed $(\mathrm{m} / \mathrm{s})$ & 5.72 & 7.44 & 5.95 \\
\hline Max speed (m/s) & 22.8 & 24.0 & 25.2 \\
\hline time of Top speed & 16 & 14 & 6 \\
\hline $\operatorname{calm}(\mathrm{m} / \mathrm{s})$ & 2 & 2 & 2 \\
\hline Frequency of calm winds (\%) & 7 & 3 & 11 \\
\hline
\end{tabular}

For the data analysis of the sites it was necessary to examine more elaborate representations of raw data recorded by the stations, as shown in Fig. 4 and Table III.
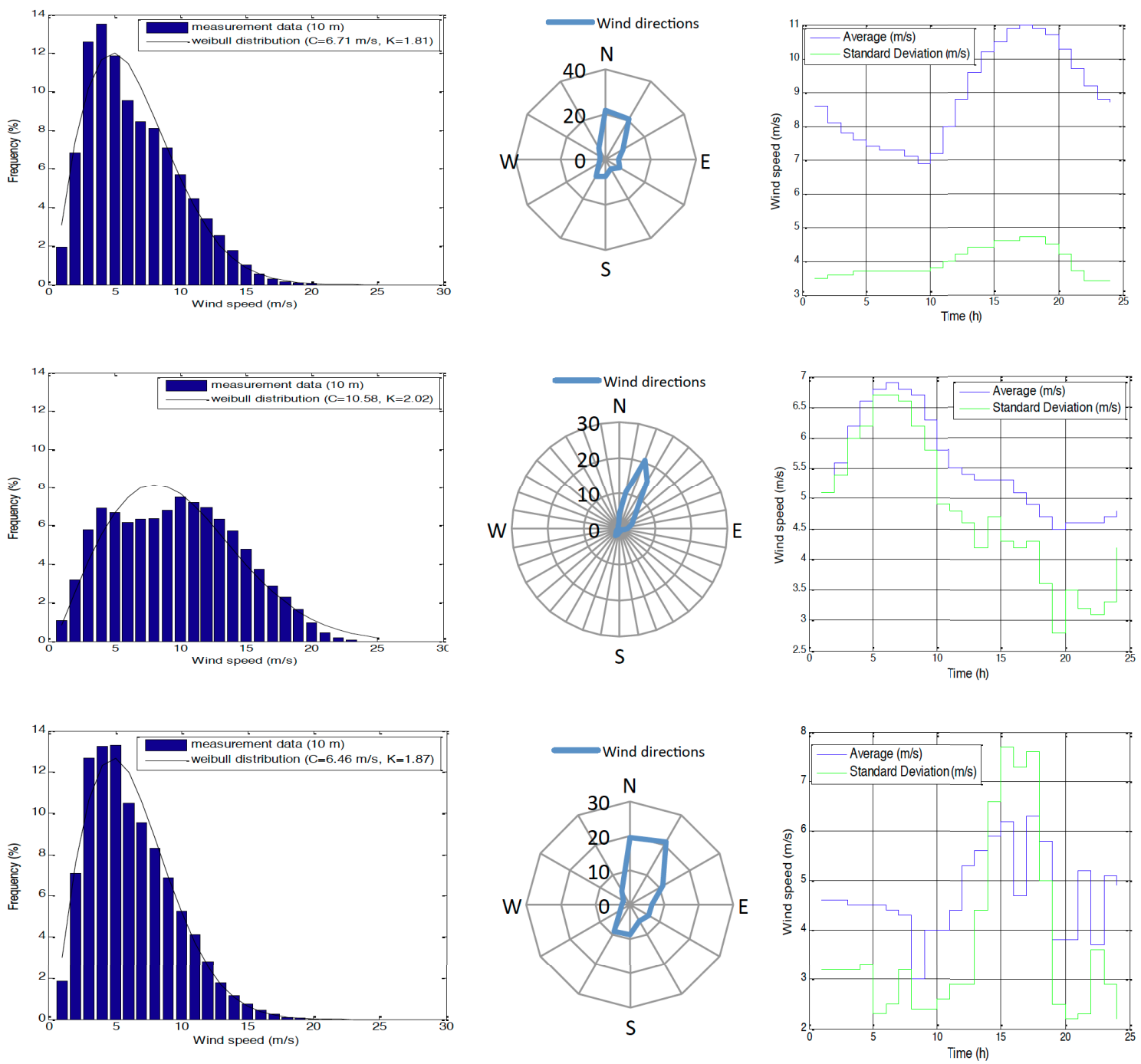

Figure 4. Wind speed statistics, Wind direction statistics and Diurnal pattern curves for, AISSI CAP SIM and CAP HDID sites. 
PAPER

Evaluation of Potential Wind ENERgy Sites In the Province of Essaouira IN Morocco

TABLE III.

CALMS ANALYSIS

\begin{tabular}{|c|c|c|c|c|c|c|}
\hline \multirow{2}{*}{$\begin{array}{c}\text { site } \\
C A L M S\end{array}$} & \multicolumn{2}{|c|}{ CAP HDID } & \multicolumn{2}{|c|}{ AISSI } & \multicolumn{2}{|c|}{ CAP SIM } \\
\hline & $F<2.5 \%$ & $F<4.5 \%$ & $F<2.5 \%$ & $F<4.5 \%$ & $F<2.5 \%$ & $F<4.5 \%$ \\
\hline 1 & 15 & 41.3 & 14.7 & 40.8 & 7.1 & 19.8 \\
\hline 2 & 14 & 40.1 & 13.9 & 39.7 & 6.7 & 19.4 \\
\hline 4 & 13 & 39.4 & 13.2 & 39 & 6.4 & 19 \\
\hline 8 & 12 & 38.4 & 12.2 & 38.1 & 6 & 18.5 \\
\hline 16 & 11 & 37 & 11 & 36.8 & 5.5 & 18 \\
\hline 32 & 9.8 & 35.1 & 9.3 & 35.2 & 4.9 & 17.2 \\
\hline 64 & 7.1 & 32.8 & 6.7 & 32.9 & 3.9 & 15.8 \\
\hline 128 & 3.9 & 29.5 & 4 & 29.4 & 2.6 & 14 \\
\hline 256 & 1.1 & 24.5 & 1.5 & 24.3 & 1 & 11.1 \\
\hline 512 & 0.2 & 15.6 & 0 & 15.4 & 0.5 & 6.7 \\
\hline 1024 & 0 & 5.8 & 0 & 5.2 & 0.3 & 1.8 \\
\hline 2048 & 0 & 1.4 & 0 & 0.7 & 0 & 0 \\
\hline 4096 & 0 & 0 & 0 & 0 & 0 & 0 \\
\hline
\end{tabular}

We attempted to define the evolution by adjusting the series being considered by using appropriate curves representative of the cloud (reference site wind speeds and target site wind speeds) to determine the adjustment coefficient between the wind resource references, since we know the chronology of the annual average speeds.

The results in Table IV show that the mast of the CAP HDID is very well correlated with the synoptic network from the National Center for Atmospheric Research (NCAR), but the masts CAP SIM and AISSI have low correlations relative to the site JBEL HDID.

TABLE IV.

LINEAR CORRELATIONS BETWEEN MEASUREMENTS ON THREE SITES STUDY AT A HEIGHT OF $10 \mathrm{M}$ AND THAT OF THE REFERENCE STATION.

\begin{tabular}{|l|c|c|c|}
\hline \multicolumn{1}{|c|}{ Site } & CAP HDID & CAP SIM & AISSI \\
\hline Adaptation coefficient & $\mathrm{R}$ & $\mathrm{R}$ & $\mathrm{R}$ \\
\hline NCAR network & 0.82 & 0.40 & 0.32 \\
\hline
\end{tabular}

The site CAP HDID was considered as the only study site in the following and on which we built recovery of long-term data.

\section{VERTICAL EXTRAPOLATION}

Another important factor is that in general, the measurements wer not taken at the height they should ideally be made (height of the future turbine hub).

Power law was used to determine the vertical profile of the wind. Proposed by Reed and adopted by Mikhail et al. [5], it is written:

$V=V_{0}\left(\frac{H}{H_{0}}\right)^{n}$

Where $n$ is the exponent of Hellmann, which generally varies between 0.1 and 0.4 depending on the roughness of ground, it characterized the vertical shear of the horizontal wind velocity. If there is no specific information, IEC61400-1 [6] standard recommends applying a coefficient 0.2 , which corresponds to a roughness of approximately $0.10 \mathrm{~m}$. The exponent $\mathrm{n}$ is a function of the reference speed $V_{0}$. Moreover, the $V$ and $V_{0}$ speeds are connected by the following relationship:

$V=\alpha V_{0}^{\beta}$

For the resolution, we introduced two parameters $a$ and $b$ for determining the parameters $n, \alpha$ and $\beta$ of the system. Thus:
$V=V_{0}\left(\frac{H}{H_{0}}\right)^{a}\left(\frac{H}{H_{0}}\right)^{n-a}$

By identification of the terms within the system, we get: $\alpha=\left(\frac{H}{H_{0}}\right)^{a}$

$V_{0}^{\beta}=V_{0}\left(\frac{H}{H_{0}}\right)^{n-a}$

After linearization gives:

$b=\frac{\beta-1}{\log \left(\frac{H}{H_{0}}\right)}=\frac{n-a}{\log (V)}$
$\beta=1+b \cdot \log \left(\frac{H}{H_{0}}\right)$
$n=a+b \cdot \log \left(V_{0}\right)$

Practically at the three study sites, the measurements were made at a height of $10 \mathrm{~m}$. Taking into consideration the strong correlation between the measurements taken for the study masts, with the mast reference and the fact that these sites are located in the same geographical and climatic conditions, it was assumed that the coefficients $n$ are the same to extrapolate the measured speed $10 \mathrm{~m}$ on the study site for higher levels.

Necessary conditions proposed by JC Kaimal [7] for the implementation of the power law:

- Installing the pylon to measure the coefficient of Hellmann must be on flat and homogeneous ground

- Measurements of various parameters should be performed at the same time and integrated over the same period

- The measurement period must be greater than the time constant of the sensor

- A 0,05 m.s-1 precision is required for the measurement of the average speed

- The number of measurement points requested must check the following criterion:

$N \geq\left(\frac{\sigma(x)}{\Delta x}\right)^{2}$

Where $N$ is the number of points, $\sigma(x)$ the standard deviation of $x$ and $\Delta x$ is the desired precision. 
Shear wind speeds depend primarily on the ground roughness and thermal stability class. Thus, since the thermal stability is known seasonally, daily, and according to the meteorological situation, the vertical velocity profile will be highly dependent on the weather. That is why we chose this one to calculate for each time step (every 10 minutes). The measurements taken for 12 months at several heights allowed focusing gradually on the value of $n$ in that specific location. But as we did have not this option, we chose otherwise.

Vertical extrapolation for wind speed of the CAP HDID station through extrapolation of the wind speed profile as a function of height on the reference model and the measurements were made at multiple levels. These profiles were dependent on the implicit function of atmospheric stability and where we often take the case of a neutral atmosphere in order to cancel.

The CAP HDID station measurements were made at a height of $10 \mathrm{~m}$. Considering the high correlation between the measurements to the CAP HDID mast and that of our reference model and the fact that these sites are in the same geographical and climatic conditions, it was assumed that the coefficients $\mathrm{n}$ are the same to extrapolate the measured $10 \mathrm{~m}$ speed on the CAP HDID site at higher levels. Thus applying the previously defined power law found the vertical profile of the CAP HDID site illustrated in Figure 5.

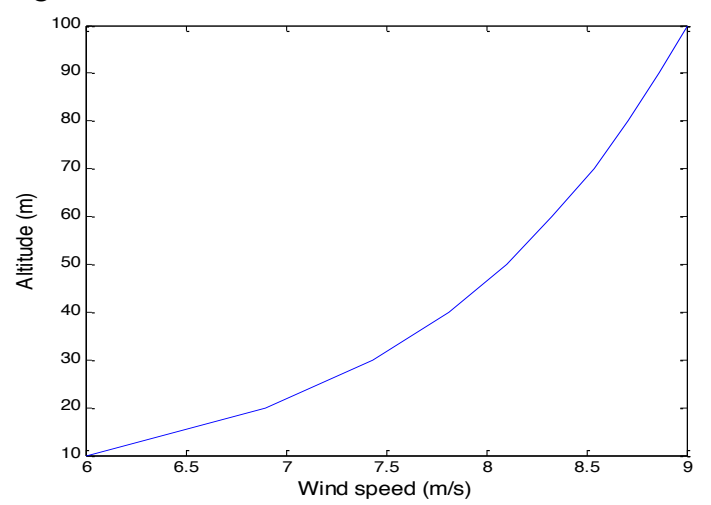

Figure 5. Measures of the Hellmann coefficient from the speed vertical profile

\section{Statistically Predict The Wind}

A recurring problem for the designer wind farms is the long-term evaluation of wind resources for the project. Regardless of cost, potential wind measurements at the study site are often limited to minimum and short duration, which is inconsistent with the need to know the wind speed over at least a 10 year period to reflect meteorological cycles of long duration.

The solution is to connect the measurements to the measurements of studies on a reference site, typically by a meteorological service, that have been conducted for a long time.

\section{A. Method Measurement Correlations Predictions}

The algorithms measure prediction correlations (MCP) are used to predict the wind resource on the target sites for the development of wind energy. MCP methods connect the wind data (speed and direction) measured at the target site, generally over a period of up to one year, and simultaneous data on a reference site nearby. The model then uses the long-term data on the reference site to predict the long-term wind speed and direction for the target location. The purpose of the MCP method is usually to characterize wind speed distributions, depending on the wind direction at the target site, to be able to determine the annual energy capture of a wind farm located on the target site.

While the prediction of wind speed generally takes into account the wind direction on the reference site, the wind direction is generally modeled independent of the wind speed. The following section of this document focuses on the prediction of the wind speed at the target site.

\section{B. Principle}

In general, MCP algorithms use models to predict wind speed at the target site in regard to the wind speed and other conditions on the reference site.

Table V [8] shows many exhaustive studies have been conducted and multiple models have been developed by researchers, such as the model by Landberg and Mortenson [13, 14], the model by Nielsen et al. [11], the model by Riedel et al. [12], the model by Woods and Watson [15], the model by Vermeulen et al. [16], the model by Derrick [9, 10], and the model by Joensen et al. [17] (Table V). The adjusted model is then applied to long-term data at the reference site to predict long-term data on the target site; the choice of model depends on the accuracy of the prediction and the calculation time.

One of MCP models most widely used, developed by Derrick $[9,10]$, was chosen for this study because it provides sufficient accuracy and reduction computational time. Derrick $[9,10]$ used linear regression to characterize the relationship between the reference's and target site's wind speeds:

$y=m x+b$

Where $\mathrm{y}$ is the predicted wind speed at the target site, $x$ is the observed wind speed at the reference site, $m$ and $b$ are the slope and offset determined from linear regression. Separate parameters were calculated for data in twelve direction bins defined by wind direction at the reference site. He also pointed out that linear regression could be used for models of the form:

$y=a x^{b}$

In this case, the linear regression would be performed after taking the logarithm of both sides of the equation. He discussed the use of the variances and co-variances calculated from the linear regression to determine confidence intervals for the predicted mean wind speed, assuming that the assumptions of the linear regression approach apply. Finally, based on the available data, Derrick concluded that at least 8 months of data were needed to minimize uncertainties in the results. In [9], Derrick considered the use of polynomials to characterize differences in wind direction at the two sites. Due to scatter in the data, the predicted wind direction distribution only roughly approximated the known distribution.

Finally, to improve energy capture estimates, Derrick suggested not using data at low wind speeds $(04 \mathrm{~m} / \mathrm{s})$ in the determination of the correlation, as wind vane behavior is erratic and wind turbines do not operate at low wind speeds. Not using low wind speed data resulted in incorrect estimates of the overall mean wind speed. 
TABLE V.

OVERVIEW OF SEVEN MCP APPROACHES FOUND IN THE LITERATURE, INCLUDING COMPUTATIONAL APPROACH, DATA PROCESSING DETAILS AND THE REPORTED METHOD OF EVALUATION

\begin{tabular}{|c|c|c|c|}
\hline Reference & Approach & Data processing & Method of evaluation \\
\hline Derrick $[9,10]$ & $\begin{array}{l}\text {-Speed: linear fit } \\
\text {-Direction: none or } \\
\text { polynomial fit }\end{array}$ & Data filtering & $\begin{array}{c}\text {-Fit length: annual mean, error, } \% \text {, annual } \\
\text { energy } \\
\text { error, } 15 \text { years of data } \\
\text {-Overall method: } 15 \text { years, sector average }\end{array}$ \\
\hline Nielsen et al. [11] & $\begin{array}{l}\text { Linear transformation: using } \\
\qquad \mathrm{u}, \mathrm{v}\end{array}$ & $\begin{array}{l}\text {-Band-limited correlation } \\
\text {-Different averaging periods }\end{array}$ & $\begin{array}{c}\text {-Averaging period: Pearson's } r \text { for each sector } \\
\text { fit } \\
\text { Overall method: } \mathrm{u} 3,7 \text { years of data }\end{array}$ \\
\hline Riedel et al. [12] & $\begin{array}{l}\text {-Speed: quadratic fit } \\
\text {-Direction: Chebyshev } \\
\text { polynomials }\end{array}$ & $\begin{array}{l}\text {-Dynamic sector positioning } \\
\text {-Minimization of residuals and pre- } \\
\text { diction errors }\end{array}$ & $\begin{array}{c}\text {-Fit length: median, quartiles of energy yield } \\
\text { error (using power curve) } \\
\text { Visual comparison of wind roses } \\
\text {-Onshore: } 1 \text { year, multiple sites } \\
\text { Offshore: } 6 \text { years } \\
\end{array}$ \\
\hline $\begin{array}{c}\text { Landberg and } \\
\text { Mortenson }[13,14]\end{array}$ & $\begin{array}{l}\text {-Speed: linear fit } \\
\text {-Direction: none }\end{array}$ & Cross-correlation vs. distance & $\begin{array}{c}\text {-Fit length: scatter of predicted mean with } \\
\text { different Experiments } \\
-2 \text { years of data } \\
\end{array}$ \\
\hline $\begin{array}{l}\text { Woods and Watson } \\
{[15]}\end{array}$ & $\begin{array}{c}\text {-Speed: linear fit } \\
\text {-Direction: matrix bins }\end{array}$ & Matrix bin count cut-off level & $\begin{array}{l}\text { Direction bins: sector means, sector counts. } 100 \\
\text { days of data }\end{array}$ \\
\hline Vermeulen et al. [16] & $\begin{array}{c}\text {-Speed: linear fit } \\
\text {-Direction: matrix bins }\end{array}$ & $\begin{array}{c}\text { Consideration of criteria for } \\
\text { using method }\end{array}$ & $\begin{array}{c}\text { Direction bins: sector means, sector counts. } 1 \\
\text { year of data }\end{array}$ \\
\hline Joensen et al. [17] & $\begin{array}{l}\text {-Speed: quadratic fit, to } \\
\text { address atmospheric stability } \\
\text {-Direction: constant offset }\end{array}$ & $\begin{array}{c}\text {-Rotate axes for highest } \\
\text { correlation coefficient } \\
\text {-Fit for direction neighborhood }\end{array}$ & $\begin{array}{c}\text { Visual comparison of speed distributions, } 2 \\
\text { years of data }\end{array}$ \\
\hline
\end{tabular}

\section{Reconstitution of long-term data}

Measurements were taken on a one-year cycle; then they were compared with the data of the winds of a meteorological station chosen for the quality of its correlation with measurements recorded during the year and for which it was possible to go back in time over a period as long as possible. Thus, according to this approach, statistical measurements this year were representative of all years in this area.

These were the statistics that determined the feasibility of the wind farm. It is therefore recommended to give particular attention, and for greater security, to the consexpertise results.

The correlation of the wind direction is not a key parameter due to the wind turbines' orientation ability, but it is necessary to examine the influence of wake effects in wind farms. Moreover, the wind direction in the site study is highly dependent on the proximity relief.

The correlation coefficients obtained from the measurement period were then applied to measurements recorded for several years by the reference station to derive a distribution of long-term rates on the site. The correlation was established by the directional wind sector. The quality of the prediction depended first on the degree of correlation between the site and the meteorological station of reference and second on the quantity and quality of the data available to the reference station.

\section{PRELIMINARY DESIGN PARK}

When the site was identified and the decision was made to invest in its development, we could begin to preliminarily design the park. The first thing to do was to define constraints to its development:

- Maximum capacity installed

- Boundaries of the site

- Distance of roads, houses, private property boundaries
- Environmental constraints

- Minimum distance between wind turbines

- Air corridors

After defining the constraints, the first conceptualization could be provided. This gave an idea about the size of the development to be expected. Second, we could compare different machine sizes (diameters) to estimate the recoverable capacity of the park.

The resource of the site wind was the key parameter for determining the economic viability of a wind farm in this location. This is why it was necessary to have very strict in situ measurements. The preliminary design of the park allows planning more rigorous measurements in the most appropriate locations.

\section{COMPARISONS OF MACHINES WITH DIFFERENT HuB HEIGHTS}

\section{A. Selection of wind turbines}

The first machine selection was done according to the range and the turbulence of the wind acting on the study area. For this first criterion, we could limit our choice to the number of turbines. Subsequently, a second comparison was made on the basis of the power generation performance on our site.

\section{B. Annual Energy Production and utilization rates}

For a given probability distribution of wind speed $f(V)$ is a known power curve of an electric machine, $P(V)$, the Annual Energy Production (AEP) is given by:

$$
A E P(V)=8760 \int P(V) f(V) d V
$$

Also defined $R_{u}$ utilization rate of a machine by:

$R_{u}=\frac{A E P_{n e t}}{n P_{n}}$ 
Where $A E P_{\text {net }}$ represents net annual producible, $P_{n}$, the rated power of the machine and $n$ the number of hours of year.

After analysis of the turbulence on the JBEL HDID site, deduction machines are the Class 1-A IEC standards [7], and the results are listed in the Table VI.

TABLE VI.

COMPARE MACHINES UP TO $70 \mathrm{M}$

\begin{tabular}{|l|l|l|l|l|}
\hline Machine & $\begin{array}{l}\text { Maximum } \\
\text { number of } \\
\text { turbines }\end{array}$ & $\begin{array}{l}\text { Average } \\
\text { wind } \\
\text { machine } \\
\text { (m/s) }\end{array}$ & $\begin{array}{l}\text { net AEP } \\
\text { (GWh) }\end{array}$ & $\begin{array}{l}\mathbf{R}_{\mathbf{u}} \\
\mathbf{( \% )}\end{array}$ \\
\hline $\begin{array}{l}\text { SWT82 } \\
{[18]}\end{array}$ & 18 & 10.80 & 196.257 & 53.4 \\
\hline G80 [19] & 18 & 10.06 & 181.129 & 57.4 \\
\hline N80 [20] & 18 & 11.54 & 207.782 & 52.7 \\
\hline N90 [20] & 18 & 11.08 & 216.265 & 59.6 \\
\hline
\end{tabular}

Based on the utilization rate, the Nordex N90 machine seemed to be one that allowed for better production in the study area.

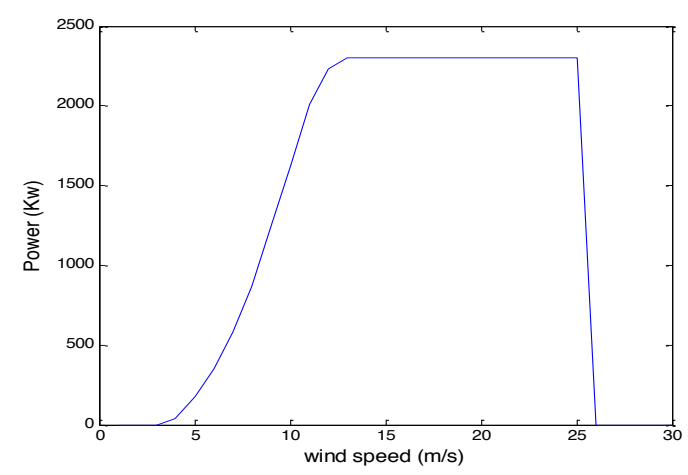

Figure 6. Characteristic of the power curve for Nordex N90.

As shown in Table VII, using an average wind machine of $11.08 \mathrm{~m} / \mathrm{s}$ with an average producible by an equal machine $12014 \mathrm{MWh} /$ year, followed with 18 turbines, it would be possible to obtain a capacity of $41.4 \mathrm{MW}$ for a total utilization rate of $59.6 \%$.

\section{CONCLUSION AND SUGgestion}

The wind atlas describes the wind potential of the Jebel HDID site for developing wind power projects. Local meteorological data and field observations allowed us to confirm the results of this study. The wind atlas confirmed that this site has good ventilation conditions for exploiting this source of renewable energy. A map of the wind speed was the basis for the selection of potential wind projects and the orientation of the action. However, the wind data (speed, direction) for the different stations that we had presented errors, sometimes for months, so it is recommended that repairs be made to measuring stations.

The results risks were also affected by some uncertainties that we could not quantify. Indeed, the data reconstitution step of long term wind involves two successive correlations, and the vertical extrapolation conditions were not all satisfied.
TABLE VII.

THE PRODUCIBLE OF 18 WIND TURBINES OF JEBEL HDID PARK

\begin{tabular}{|c|c|c|c|}
\hline Site & Location[m] & $\begin{array}{l}\text { Elevation } \\
{[\mathrm{m}]}\end{array}$ & $\begin{array}{l}\text { Net AEP } \\
{[\text { GWh] }}\end{array}$ \\
\hline $\begin{array}{l}\text { Turbine } \\
\text { site } 01\end{array}$ & $\begin{array}{l}(448645, \\
7,3507529,0)\end{array}$ & 512 & 11,922 \\
\hline $\begin{array}{l}\text { Turbine } \\
\text { site } 02\end{array}$ & $\begin{array}{ll}(449071, & 6, \\
3507728,0) & \end{array}$ & 570 & 12,174 \\
\hline $\begin{array}{l}\text { Turbine } \\
\text { site } 03\end{array}$ & $\begin{array}{ll}450661, & 9, \\
3508154,0) & \\
\end{array}$ & 630 & 12,185 \\
\hline $\begin{array}{l}\text { Turbine } \\
\text { site } 04\end{array}$ & $\begin{array}{ll}(451684, & 3, \\
3508296,0) & \\
\end{array}$ & 602 & 11,807 \\
\hline $\begin{array}{l}\text { Turbine } \\
\text { site } 05\end{array}$ & $\begin{array}{ll}(449639, & 6, \\
3507899,0) & \\
\end{array}$ & 588 & 12,244 \\
\hline $\begin{array}{l}\text { Turbine } \\
\text { site } 06\end{array}$ & $\begin{array}{ll}(451087, & 9, \\
3508183,0) & \end{array}$ & 630 & 12,277 \\
\hline $\begin{array}{l}\text { Turbine } \\
\text { site } 07\end{array}$ & $\begin{array}{l}(452110,2, \\
3508381,0)\end{array}$ & 581 & 11,509 \\
\hline $\begin{array}{l}\text { Turbine } \\
\text { site } 08\end{array}$ & $\begin{array}{ll}(455120, & 5, \\
3509631,0) & \\
\end{array}$ & 605 & 11,63 \\
\hline $\begin{array}{l}\text { Turbine } \\
\text { site } 09\end{array}$ & $\begin{array}{ll}(455574, & 9, \\
3509943,0) & \end{array}$ & 632 & 11,798 \\
\hline $\begin{array}{l}\text { Turbine } \\
\text { site } 10\end{array}$ & $\begin{array}{ll}(456029, & 2, \\
3510313,0) & \end{array}$ & 660 & 12,041 \\
\hline $\begin{array}{l}\text { Turbine } \\
\text { site } 11\end{array}$ & $\begin{array}{l}(456455,2, \\
3510625,0)\end{array}$ & 690 & 12,511 \\
\hline $\begin{array}{l}\text { Turbine } \\
\text { site } 12 \\
\end{array}$ & $\begin{array}{l}(456966, \\
4,3510881,0)\end{array}$ & 690 & 12,226 \\
\hline $\begin{array}{l}\text { Turbine } \\
\text { site } 13 \\
\end{array}$ & $\begin{array}{l}(457931,9, \\
3511534,0)\end{array}$ & 676 & 12,346 \\
\hline $\begin{array}{l}\text { Turbine } \\
\text { site } 14\end{array}$ & $\begin{array}{l}(457477,6, \\
3511193,0)\end{array}$ & 690 & 12,286 \\
\hline $\begin{array}{l}\text { Turbine } \\
\text { site } 15\end{array}$ & $\begin{array}{l}(458386,3, \\
3511875,0)\end{array}$ & 635 & 12,2 \\
\hline $\begin{array}{l}\text { Turbine } \\
\text { site } 16\end{array}$ & $\begin{array}{l}\text { (450094,350806 } \\
9)\end{array}$ & 612 & 11,842 \\
\hline $\begin{array}{l}\text { Turbine } \\
\text { site } 17\end{array}$ & $\begin{array}{ll}(454552, & 5, \\
3509375,0) & \\
\end{array}$ & 600 & 11,851 \\
\hline $\begin{array}{l}\text { Turbine } \\
\text { site } 18\end{array}$ & $\begin{array}{ll}(452593, & 0, \\
3508609,0) & \end{array}$ & 570 & 11,418 \\
\hline
\end{tabular}

\section{REFERENCES}

[1] National Center for Atmospheric Research, http://ncar.ucar.edu/

[2] http://www.wwindea.org/wwea-publishes-half-year report-2014/

[3] http:// www.one.org.ma/

[4] Ministry of Energy and Mines of Morocco.

[5] Mikhail et al. AS and CG Justus, Comparison of height extrapolation models and sensitivity analysis, wind engineering, 1981.

[6] international electrotechnical commission, http:// www.iec.ch

[7] C. kaimal, Sensors and techniques for direct measurement of turbulent fluxes and profiles in the atmospheric surface layer, Atmospheric technology, 1975.

[8] Anthony L. Rogersa,, John W. Rogersb, James F. Manwella, Comparison of the performance of four measure-correlate-predict algorithms, USA, 2005

[9] A. Derrick, Development of the measure-correlate-predict strategy for site assessment, Proceedings of the BWEA, 1992.

[10] A. Derrick, Development of the measure-correlate-predict strategy for site assessment, Proceedings of the EWEC, 1993.

[11] M. Nielsen, L. Landberg, N.G. Mortensen, R.J. Barthelmie, A. Joensen, Application of measure-correlate-predict approach for wind resource measurement, Proceedings of the EWEA, 2001.

[12] V. Riedel, M. Strack, Robust approximation of functional relationships between meteorological data: alternative measure-correlatepredict algorithms, Proceedings of the EWEA, 2001. 
Evaluation of Potential Wind EnERgy Sites In the Province of Essaouira in Morocco

[13] L. Landberg, N.G. Mortenson, A comparison of physical and statistical methods for estimating the wind resource at a site, Proceedings of the BWEA, 1993

[14] N.G. Mortensen, L. Landberg, I. Troen, E.L. Petersen, Wind Atlas Analysis and Application Program, vol. 2:Users Guide. Riso-I666(ENN) (v.2). Riso National Laboratory, Roskilde, Denmark, 133 pp.

[15] J.C. Woods, S.J. Watson, A new matrix method of predicting long-term wind roses with MCP, J. Wind Eng. Ind. Aerodyn. 66 (2) (1997) 85-94. http://dx.doi.org/10.1016/S01676105(97)00009-3

[16] P.E.J. Vermuelen, A. Marijanyan, A. Abrahamyan, J.H. den Boon, Application of matarix MCP analysis in mountainous Armenia, Proceedings of the EWEA, 2001.

[17] A. Joenson, L. Landberg, H. Madsen, A new measure-correlatepredict approach for resource assessment, Proceedings of the EWEC, 1999.

[18] http:// www.siemens.com

[19] http://www.gamesacorp.com

[20] http:// www.nordex-online.com

\section{AUTHORS}

Daoudi Mohammed, is a doctoral student, Laboratory of Engineering Didactic and Dynamic Systems, FST Settat, Hassan $1^{\text {st }}$ University, Morocco (e-mail: mohammed.daoudi87@gmail.com).

Elkhouzai Elmostapha, is a Professor in the Department of Physics, Laboratory of Engineering Didactic and Dynamic Systems, FST Settat, Hassan $1^{\text {st }}$ University, Morocco.

Zakkari Mohammed, is a Professor in the Department of Mathematics, Laboratory of Engineering Didactic and Dynamic Systems, FST Settat, Hassan $1^{\text {st }}$ University, Morocco.

Submitted 18 January 2015. Published as resubmitted by the authors 10 October 2015. 